J. Dairy Sci. 95:3181-3189

http://dx.doi.org/10.3168/jds.2011-4606

(C) American Dairy Science Association ${ }^{\circledR}$, 2012. Open access under CC BY-NC-ND license.

\title{
Variation among individual dairy cows in methane measurements made on farm during milking
}

\author{
P. C. Garnsworthy, ${ }^{1}$ J. Craigon, J. H. Hernandez-Medrano, and N. Saunders \\ The University of Nottingham, School of Biosciences, Sutton Bonington Campus, Loughborough LE12 5RD, UK
}

\begin{abstract}
The objective of this study was to quantify on-farm variation between and within cows in methane emissions measured during milking, and to determine which factors are related to this variation. Methane emission rate during milking (MERm) was recorded at milking using methane analyzers installed in automatic (robotic) milking stations for 215 cows over a period of 5 mo. Between-cow variation in MERm (mean 2.07, SD $0.629 \mathrm{~g} / \mathrm{min}$ ), was greater than within-cow variation and was related to variation in body weight, milk yield, parity, and week of lactation. Estimation of daily methane emissions from MERm data, using an equation derived from comparisons with respiration chamber data, produced estimates that ranged from 278 to $456 \mathrm{~g}$ of $\mathrm{CH}_{4} / \mathrm{d}$ and were commensurate with values predicted from metabolizable energy requirements for observed body weight and milk yield. It is concluded that methane emissions vary considerably between dairy cows housed under commercial conditions. This variation needs to be taken into account when performing inventories or testing mitigation strategies, but it might offer opportunities for genetic selection.
\end{abstract}

Key words: methane, dairy cow, environmental impact, greenhouse gas inventory

\section{INTRODUCTION}

When calculating methane emissions by dairy cows for national greenhouse gas inventories, tier 1 methodology assumes a fixed factor for all cows and tier 2 methodology estimates methane output using gross energy (GE) intake predicted from milk yield (IPCC, 2006). Both of these approaches lead to uncertainty in estimation of total emissions because methane output varies with DMI (Grainger et al., 2007; Yan et al. 2010) and diet composition (Beauchemin et al. 2009). Furthermore, measurements of methane output from

Received June 6, 2011.

Accepted February 12, 2012.

${ }^{1}$ Corresponding author: Phil.Garnsworthy@nottingham.ac.uk animals in respiration chambers revealed considerable variability among individuals fed the same diet (Blaxter and Clapperton, 1965; Grainger et al., 2007).

High variability among individuals increases the level of replication required to obtain robust estimates of methane emissions or to assess the efficacy of mitigation strategies. On the other hand, if between-cow variation has a genetic component, then genetic variation offers the possibility to select cows for lower methane emissions.

Respiration chambers provide accurate measures of methane emissions for limited numbers of individual animals under controlled conditions, but are impractical for use on a farm scale. The sulfur hexafluoride $\left(\mathrm{SF}_{6}\right)$ tracer technique (Johnson et al., 1994) can be used under semi-commercial conditions to generate larger numbers of values for daily methane emissions by individual cows. The $\mathrm{SF}_{6}$ technique, however, requires a gas collection apparatus attached to the cow, insertion of rumen boluses to release $\mathrm{SF}_{6}$, and frequent cow handling, all of which can interfere with cow behavior.

Measurement of methane produced through eructation by cows during milking is a noninvasive technique that has no effect on cow behavior or performance. In our previous study, methane emissions estimated by this technique were positively related to daily milk yield in 82 cows monitored at up to 6 milkings between the hours of 0800 and $1800 \mathrm{~h}$ and, for a further 12 cows monitored at each milking over a 10-d period, showed a high correlation with measurements of daily methane production made subsequently on the same cows in respiration chambers (Garnsworthy et al., 2012). Variation among cows was high, however, even at the same level of milk yield, suggesting a requirement for further investigation. The objective of the current study was to quantify on-farm variation between and within cows in methane emissions measured during milking, and to determine which factors are related to this variation.

\section{MATERIALS AND METHODS}

Animal work was conducted under authority of the UK Animal (Scientific Procedures) Act 1986, and approval was obtained from the University of Nottingham 
animal ethics committee before commencement of the study.

\section{Animals, Management, and Methane Recording}

All cows used in this study were Holstein-Friesians at the Nottingham University Dairy Centre (Sutton Bonington, Leicestershire, UK; average annual milk yield 10,000 L/cow). Housing, feeding, and milking procedures were as described for experiment 2 in Garnsworthy et al. (2012). For the current study, all cows were on the same feeding regimen, which consisted of a partial mixed ration (PMR; Table 1) fed ad libitum, plus concentrates fed during milking in automatic milking stations (Lely Astronaut A3; Lely UK Ltd., St Neots, UK) at the rate of $1.6 \mathrm{~kg} / \mathrm{d}$ plus $0.16 \mathrm{~kg} / \mathrm{L}$ of milk yield above $23 \mathrm{~L} / \mathrm{d}$. Methane concentrations in air released by eructation were measured continuously at each milking and eructation data (peak area and frequency) were used to calculate individual daily means for methane emission rate during milking (MERm), as described by Garnsworthy et al. (2012).

To examine variation in MERm between and within cows, MERm was recorded at each milking for 215 cows over a period of 5 mo to provide 14,533 daily mean values for MERm. Not all cows were present for the whole 5-mo period, due to the dynamic nature of the

Table 1. Formulation and composition of the partial mixed ration (PMR) fed to cows throughout 5 mo of monitoring methane emission rates during milking

\begin{tabular}{lc}
\hline Item & Value \\
\hline Ingredient (g/kg of DM) & \\
Grass silage & 132 \\
Maize silage & 319 \\
Whole crop silage & 126 \\
Rape straw & 50 \\
Sugarbeet pulp & 96 \\
Rapeseed meal & 132 \\
Soybean meal & 84 \\
Fat supplement ${ }^{1}$ & 23 \\
Minerals + vitamins ${ }^{2}$ & 37 \\
Composition & 461 \\
DM (g/kg) & 11.2 \\
ME (MJ/kg of DM) & 168 \\
CP $(\mathrm{g} / \mathrm{kg}$ of DM) & 359 \\
NDF (g/kg of DM) & 136 \\
Starch $(\mathrm{g} / \mathrm{kg}$ of DM) & 48 \\
Oil $(\mathrm{g} / \mathrm{kg}$ of DM) & 63 \\
Forage $(\%$ of DM) &
\end{tabular}

\footnotetext{
${ }^{1}$ Megalac (calcium salts of palm FA; Volac International Ltd., Royston, UK).

${ }^{2}$ Bibby HiPhos (ABN Ltd., Peterborough, UK), containing calcium, 18\%; phosphorus, 10\%; magnesium, $5 \%$; salt, 17\%; copper, 2,000 mg/ $\mathrm{kg}$; manganese, 5,000 mg/kg; cobalt, $100 \mathrm{mg} / \mathrm{kg}$; zinc, $6,000 \mathrm{mg} / \mathrm{kg}$; iodine, $500 \mathrm{mg} / \mathrm{kg}$; selenium, $25 \mathrm{mg} / \mathrm{kg}$; vitamin A, 400,000 IU $/ \mathrm{kg}$; vitamin $\mathrm{D}_{3}, 80,000 \mathrm{IU} / \mathrm{kg}$; and vitamin $\mathrm{E}, 1,000 \mathrm{mg} / \mathrm{kg}$.
}

herd (cows calving, being dried off, or culled). Cows participating in experiments that involved a different feeding regimen were excluded from the data set for the duration of each experiment plus 2 wk. Milk yield and BW were recorded automatically at each milking. Ambient temperature and pressure were recorded at 10-min intervals throughout the study using loggers placed in the vicinity of each methane analyzer.

To examine sire effects on MERm, pedigree data were extracted from farm records. A total of 72 sires were identified for 164 daughters in the data set. Thirty-nine sires had only 1 daughter, 11 had 2, 7 had 3, 9 had 4, 2 had 5, 3 had 7, and 1 had 15 daughters.

For comparison with other studies and prediction equations, daily methane emissions were estimated from MERm data using the equation

$$
\begin{aligned}
& \text { methane emissions }(\mathrm{g} / \mathrm{d})=252+57.2 \\
& \times \operatorname{MERm}(\mathrm{g} / \mathrm{min}) .
\end{aligned}
$$

This equation was obtained in our previous study (Garnsworthy et al., 2012) using cows monitored on farm and subsequently in respiration chambers, and on the same dietary regimen as cows in the current study.

To compare MERm-estimated methane emissions with conventional estimates, we used the following approach. Methane emissions are predicted by the Intergovernmental Panel on Climate Change (IPCC, 2006) as $6.5 \%$ GE intake, but intake of the PMR could not be measured in the current study. Therefore, GE intake $(\mathrm{MJ} / \mathrm{d})$ was predicted for each week of lactation from recorded milk yield $(\mathrm{L} / \mathrm{d})$, BW $(\mathrm{kg})$, and concentrate intake $(\mathrm{kg} / \mathrm{d})$ by 2 methods. The first method used IPCC (2006) tier-2 methodology to calculate net energy requirements for lactation, maintenance, and pregnancy, which were then converted into GE intake using energy digestibility values of $70 \%$ for PMR and $80 \%$ for concentrates. The second method used Feed into Milk (FiM; Thomas, 2004) equations to calculate ME requirements for lactation, maintenance, pregnancy, and BW change, which were then converted into GE intake using energy metabolizability values of $62 \%$ for PMR and $71 \%$ for concentrates. In both methods, energy intake from recorded concentrate intake was subtracted from total energy requirements to predict energy intake from the PMR.

\section{Statistical Analysis}

All statistical calculations were done using the Genstat 14 statistical package (Lawes Agricultural Trust, Rothamsted, UK). 
Diurnal variation in MERm was assessed using a general linear model with hour of day when milking occurred as the only factor. Effects of ambient temperature and pressure on MERm were examined by regression of daily and hourly MERm means, averaged over all cows, against daily and hourly mean, maximum, and minimum temperatures, and pressure.

Weekly mean MERm data were analyzed as linear mixed models including repeated measures using the residual maximum likelihood (REML) procedure. The model fitted fixed effects for BW (continuous), milk yield (continuous), parity (classified according to lactation number as $1,2,3$, and $\geq 4)$, pregnancy $(1=$ pregnant during a lactation; $0=$ not pregnant during a lactation), and week of lactation (discrete). For the random effects of the model, individual cows represented subjects, and weeks of the study represented time points for repeated measures. As the correlations between successive measurements on the same cow were assumed to decrease with time interval between measurements, an autoregressive error correlation model of order 1 was used. The fixed effect of pregnancy was not significant, so this factor was excluded from subsequent models. The significance of fixed effects was assessed by Wald tests and F-ratio tests, and random effects by likelihood-ratio tests. Coefficients of variation in MERm between and within cows were calculated from the variance components of the model. Repeatability of ranking according to MERm for individual cows across time was examined by calculating the Spearman rank correlation coefficient between monthly mean MERm of individual cows for each pair of the 5 mo of monitoring.

For the subset of 164 cows with identified sires, the same mixed model was used, with the inclusion of sire as either a fixed or a random effect to allow for the fact that sires can be considered either as a specific set (fixed) or drawn at random from an infinite population (random). To examine changes in methane emissions with parity and week of lactation, the model was applied to MERm-estimated daily methane emissions. To examine changes in methane emissions with week of pregnancy, the model was applied to MERm-estimated daily methane emissions for the subset of 130 cows for which subsequent calving dates were available, and week of pregnancy was used as a fixed effect instead of week of lactation. Fitted means for each week of lactation or pregnancy were subjected to nonlinear regression analysis using an asymptotic model with addition of a linear trend $\left[\mathrm{Y}=\mathrm{A}+\mathrm{B}\left(\mathrm{R}^{\mathrm{X}}\right)+\mathrm{CX}\right]$, where $\mathrm{Y}$ is estimated methane emission $(\mathrm{g} / \mathrm{d}), \mathrm{X}$ is week of lactation or pregnancy, and A, B, C, and R are fitted parameters that define the shape of the curve. Daily methane emissions estimated from MERm data were compared with daily emissions predicted by IPCC (2006) or FiM equations using Lin's concordance (Lin, 1989).

\section{RESULTS}

\section{Cow Performance Data}

Individual cow performance data recorded across the 5-mo monitoring period were as follows: DIM ranged from 1 to 366 (mean 161, SD 98); milk yield ranged from 4 to $72 \mathrm{~L} / \mathrm{d}$ (mean 33, SD 9.1); BW ranged from 373 to $813 \mathrm{~kg}$ (mean 602, SD 70); and lactation number ranged from 1 to 12 (mean 3, SD 1.6).

\section{Variation in MERm Between and Within Cows}

Considerable variation was observed among cows in mean values for MERm over the 5-mo monitoring period. The frequency of MERm means, averaged for each individual cow across the study, followed a normal distribution (Figure 1), with an overall mean of 2.07 (SD 0.629) $\mathrm{g}$ of $\mathrm{CH}_{4} / \mathrm{min}$ and a range from 0.57 to 3.6 $\mathrm{g}$ of $\mathrm{CH}_{4} / \mathrm{min}$.

When the mixed model was fitted to MERm data, significant fixed effects were found for BW $(P<0.001)$, milk yield $(P<0.001)$, parity $(P=0.002)$, and week of lactation $(P=0.016)$. Whether or not a cow was pregnant during a lactation did not affect $\operatorname{MERm}(P=$ 0.12 ), so the term for the fixed effect of pregnancy was excluded from the model. Examination of the components of variance in MERm estimated for the random effects in this mixed model revealed that the component for individual-cow variation (0.23, SE 0.03) was greater

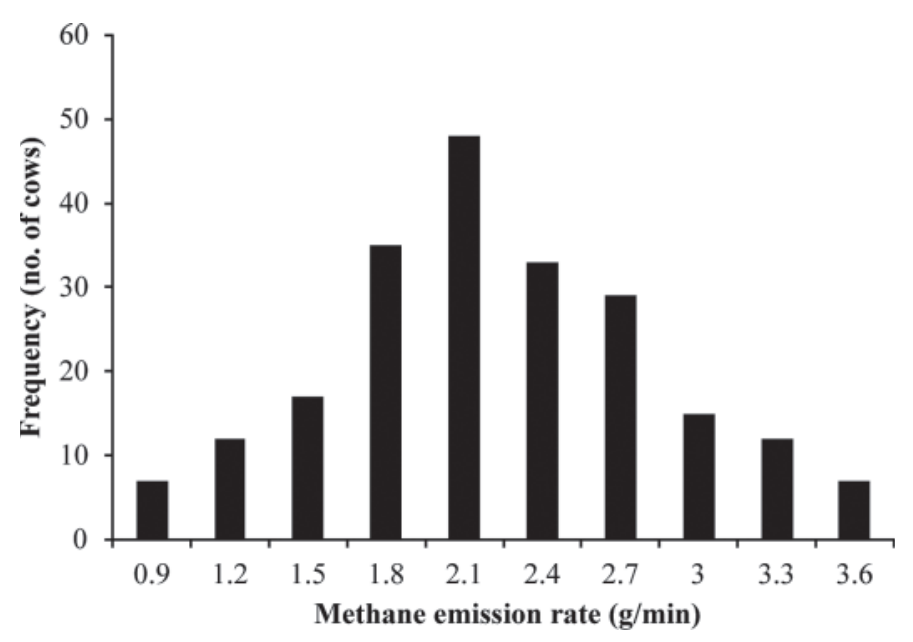

Figure 1. Frequency distribution of individual cows according to average methane emission rate during milking over a 5 -mo period. 
$(P<0.001)$ than the residual component within cows after accounting for repeated measures across weeks by a first-order autoregressive function (0.06, SE 0.02).

When the mixed model was applied to MERm data for the subset of 164 cows with identified sires, significant fixed effects remained for BW $(P<0.001)$, milk yield $(P<0.001)$, parity $(P<0.001)$, and week of lactation $(P=0.009)$, and the variance component for individual cows $(0.15$, SE 0.03$)$ was greater $(P<0.001)$ than the component for repeated measures within cows (0.08, SE 0.03). When sire was included in the model as a random effect, the sire variance component was not significant $(P=0.14)$, but sire was significant $(P=$ $0.025)$ when included as a fixed effect.

Repeatability of ranking according to MERm measurements was high for individual cows across time. Rank correlation coefficients between individual cow means in one month and the next ranged from 0.72 to $0.80(P<0.001)$. Ranking was maintained less well for longer time intervals; the rank correlation between mo 1 and 5 was 0.55 , but this was also significant $(P$ $<0.001)$.

\section{Diurnal Variation in MERm}

Variation in MERm according to time of day when milking occurred is shown in Figure 2. The herd was fed fresh PMR between 0700 and $0900 \mathrm{~h}$ each day, which is when peak feeding activity was observed, even though PMR was available ad libitum throughout the $24 \mathrm{~h}$. Methane emission rate rose sharply between 0800 and $1000 \mathrm{~h}$, remained relatively steady throughout the day, and decreased between 1800 and $0600 \mathrm{~h}$.

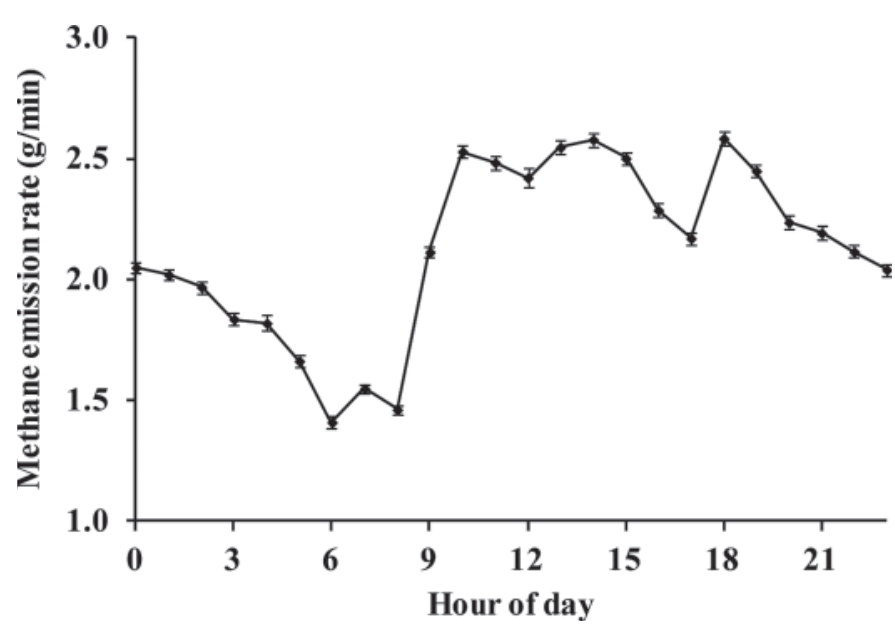

Figure 2. Diurnal variation in average methane emission rate during milking of 215 cows over a 5-mo period. Data points are means (with SE bars) of 1,000 to 3,000 milkings monitored at each hour of the day.

\section{Temperature and Pressure Effects on MERm}

Mean ambient temperature in the barn throughout the study was $8.3^{\circ} \mathrm{C}(\mathrm{SD} 3.2$, minimum -3.0 , maximum $\left.24.0^{\circ} \mathrm{C}\right)$; mean atmospheric pressure was $100.5 \mathrm{kPa}(\mathrm{SD}$ 1.36, minimum 97.8, maximum $103.0 \mathrm{kPa}$ ). No correlation was found between ambient temperature or pressure and MERm ( $\mathrm{r}=0.22$ to 0.33$)$ when daily means were examined. Within days, mean, minimum, and maximum ambient temperatures followed diurnal patterns, with lowest values at 0600 and highest at 1400 h. These times corresponded to the lowest and highest values for MERm within days, so MERm and ambient temperatures were significantly correlated $(\mathrm{r}=0.83$ for mean, 0.81 for minimum, and 0.72 for maximum hourly temperatures; $P<0.001$ ). Atmospheric pressure was not related to MERm within days.

\section{Estimates of Daily Methane Emissions}

Using the relationship between MERm and daily methane emissions measured in respiration chambers observed by Garnsworthy et al. (2012) for cows on the same dietary regimen as in the current study, the overall mean estimated for daily methane emissions was 369 $\mathrm{g}$ of $\mathrm{CH}_{4} / \mathrm{d}$ and the range was 278 to $456 \mathrm{~g}$ of $\mathrm{CH}_{4} / \mathrm{d}$. Fitting the mixed model to these data produced exactly the same statistics as MERm data because the conversion equation was a simple linear transformation. Thus, significant fixed effects were found for BW $(P<0.001)$, milk yield $(P<0.001)$, parity $(P=0.002)$, and week of lactation $(P=0.016)$. Parameter estimates from this model predicted that, allowing for all other effects in the model, daily methane emissions increased by 0.13 (SE 0.03) $\mathrm{g}$ of $\mathrm{CH}_{4} / \mathrm{d}$ per kilogram increase in $\mathrm{BW}$ and by 1.08 (SE 0.14$) \mathrm{g}$ of $\mathrm{CH}_{4} / \mathrm{d}$ per liter increase in daily milk yield. Daily methane emissions were greater $(P<$ 0.05 ) for parities 2 and 3 than for parity 1 or parities $\geq 4$ (Figure 3). Daily methane emissions increased over the first $10 \mathrm{wk}$ of lactation and were relatively constant thereafter (Figure 4). Nonlinear regression analysis of model-fitted weekly means produced the equation

$$
\begin{aligned}
& \text { daily methane emissions }\left(\mathrm{g} \text { of } \mathrm{CH}_{4} / \mathrm{d}\right)=407-103 \\
& \times\left(0.86^{\mathrm{WL}}\right)-0.63 \times \mathrm{WL}
\end{aligned}
$$

where $\mathrm{WL}=$ week of lactation. This equation accounted for $94 \%$ of variation in fitted means $(P<0.001)$ and the standard error of prediction was $4.77 \mathrm{~g}$ of $\mathrm{CH}_{4} / \mathrm{d}$.

When the mixed model was applied to the subset of 130 cows that were confirmed pregnant during the study, and week of pregnancy was included as a fixed effect, the overall effect of week of pregnancy was not 


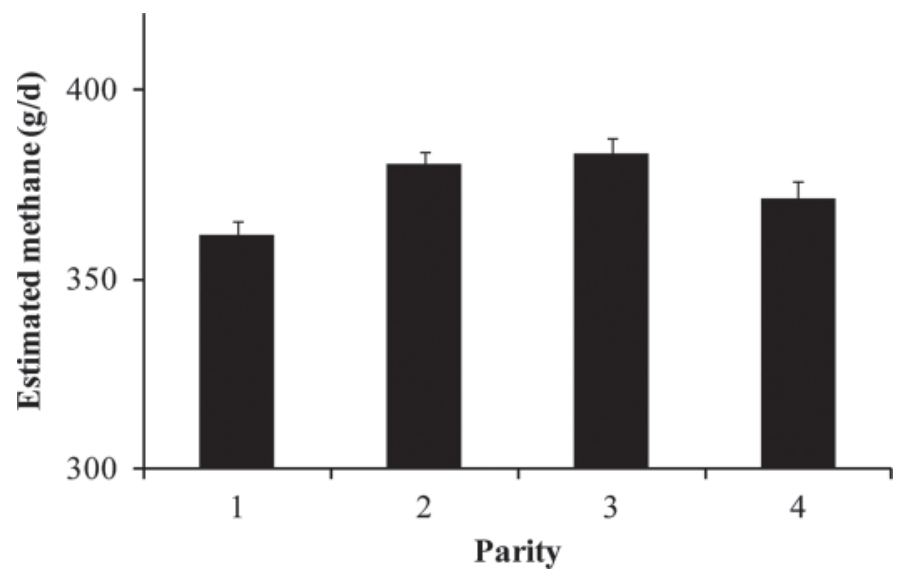

Figure 3. Average daily methane emissions by cows in different parities estimated from individual methane emission rate during milking monitored over a 5-mo period. Bars show means (with SE bars) fitted by the mixed model. Parity was classified according to lactation number as $1,2,3$, and $\geq 4$.

significant, although methane appeared to decrease from wk 20 of pregnancy onwards (Figure 5). Nonlinear regression analysis of model-fitted weekly means produced the equation

daily methane emissions ( $\mathrm{g}$ of $\left.\mathrm{CH}_{4} / \mathrm{d}\right)=413$

$$
-38 \times\left(0.95^{\mathrm{WP}}\right)-1.5 \times \mathrm{WP},
$$

where $\mathrm{WP}=$ week of pregnancy. This equation accounted for $85 \%$ of variation in fitted means $(P<$ $0.001)$ and the standard error of prediction was $3.5 \mathrm{~g}$ of $\mathrm{CH}_{4} / \mathrm{d}$.

\section{Comparisons with Predicted Daily Methane Emissions}

Mean daily methane emissions for each week of lactation estimated from MERm are compared with values predicted from observed milk yield and BW data by applying IPCC (2006) and FiM (Thomas, 2004) equations in Figure 6. The IPCC (2006) equations overestimated emissions in early lactation by up to $68 \mathrm{~g}$ of $\mathrm{CH}_{4} / \mathrm{d}(20 \%)$ and underestimated emissions in later lactation by up to $28 \mathrm{~g}$ of $\mathrm{CH}_{4} / \mathrm{d}(7 \%)$; FiM equations overestimated emissions in early lactation by up to 28 $\mathrm{g}$ of $\mathrm{CH}_{4} / \mathrm{d}(8 \%)$ and underestimated emissions substantially only in wk 1 of lactation by $13 \mathrm{~g}$ of $\mathrm{CH}_{4} / \mathrm{d}$ (3\%). Lin's concordance coefficients for comparison to MERm-estimated methane were -0.13 (95\% CI -0.33 to 0.08 ; correlation -0.18 ; bias $0.73 ; P>0.05$ ) for IPCC predictions, and 0.63 (95\% CI 0.48 to 0.74 ; correlation 0.81 ; bias $0.78 ; P<0.05)$ for FiM predic-

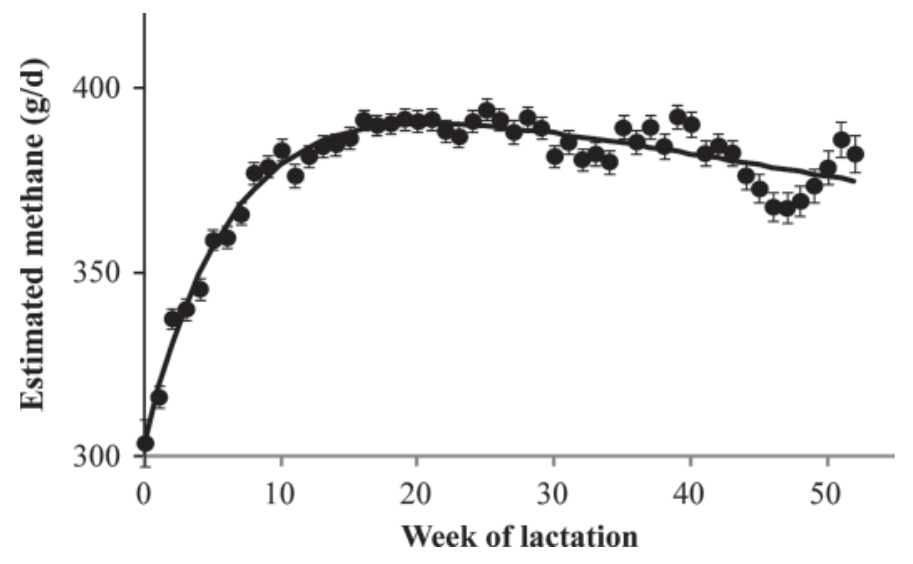

Figure 4. Change in daily methane emissions with week of lactation estimated from individual methane emission rate during milking monitored over a 5-mo period. Data points are means (with SE bars) fitted by the mixed model; the line is from a nonlinear regression model applied to fitted means.

tions. Overall means were 379 (SD 16.4) g of $\mathrm{CH}_{4} / \mathrm{d}$ for MERm-estimated methane, 383 (SD 18.7) $\mathrm{g}$ of $\mathrm{CH}_{4} / \mathrm{d}$ for IPCC-predicted methane, and 383 (SD 14.4) $\mathrm{g}$ of $\mathrm{CH}_{4} / \mathrm{d}$ for FiM-predicted methane.

\section{DISCUSSION}

The findings of this study have implications for national inventories, mitigation strategies, and methane monitoring. For the first time, methane emissions have been estimated concurrently in over 200 individual animals fed on the same diet and housed under commercial conditions over a prolonged period of time. This has

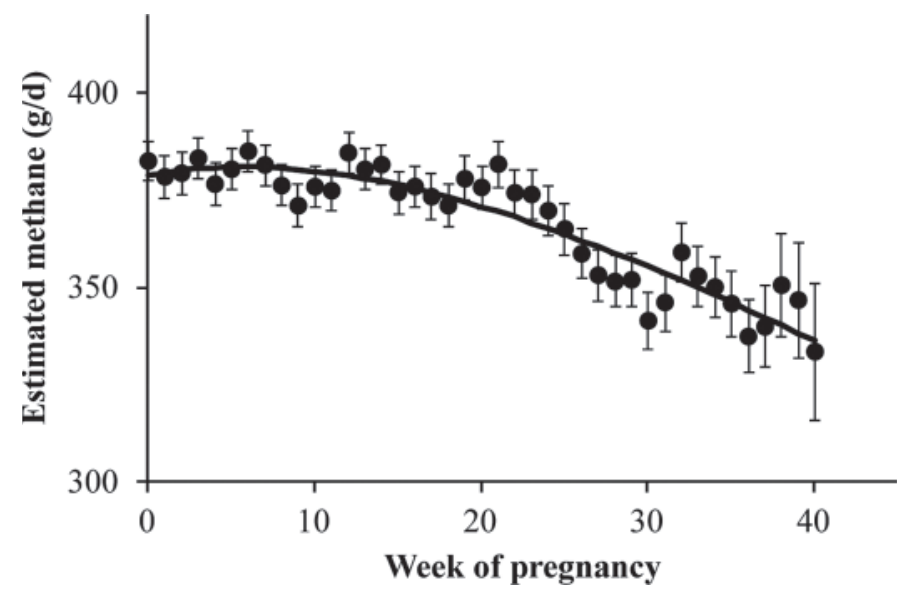

Figure 5. Change in daily methane emissions with week of pregnancy estimated from individual methane emission rate during milking. Data points are means (with SE bars) fitted by the mixed model; the line is from a nonlinear regression model applied to fitted means. 


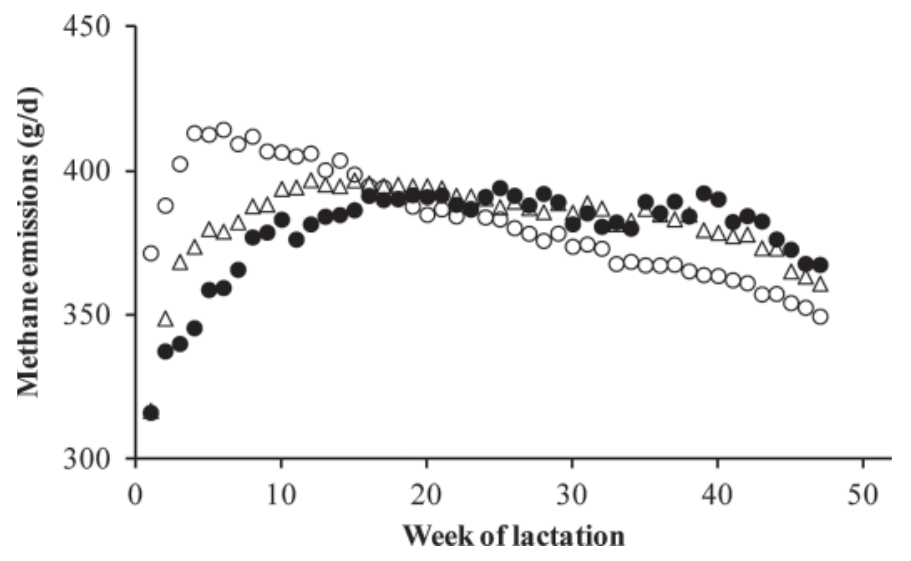

Figure 6. Daily methane emissions for each week of lactation estimated from individual methane emission rate during milking monitored over a 5-mo period (-), or predicted from recorded BW and milk yield using IPCC (2006) equations (O) or using Feed into Milk (Thomas, 2004) equations $(\Delta)$.

revealed a high degree of variability between individuals, which needs to be accounted for when compiling an inventory or testing the success of mitigation strategies. Variation between cows was significantly greater than variation within cows, suggesting that MERm estimates result from real and consistent differences between cows in their rate of methane emissions by eructation during milking.

\section{Level of Variation}

In classical feed evaluation studies, animal variation in methane output was minimized by feeding fixed amounts of food to animals in respiration chambers; nevertheless, significant variation between animals remained. Blaxter and Clapperton (1965) analyzed results of 23 investigations in which sheep were offered the same amount of the same diet and 30 investigations in which intake was scaled according to BW. In both analyses, differences between individual sheep were highly significant and the ratio of between-animal to within-animal variation in methane output was 5 for fixed intake and 12 for scaled intake. Coefficients of variation were 7 to $8 \%$ between animals and 5 to $7 \%$ within animals.

Variability between animals in methane output was greater in studies where feed was offered ad libitum. Yan et al. (2010) analyzed data from 20 energy metabolism studies involving 579 lactating dairy cows fed ad libitum in respiration chambers and found a coefficient of variation between animals for daily methane output of $17.1 \%$, which was of similar magnitude to the coefficient of variation for daily GE intake (19\%). Ellis et al. (2010) summarized results from 16 calorimetry studies of dairy cows in which coefficients of variation ranged from 3 to $34 \%$ for methane output and from 2 to $19 \%$ for DMI; studies with greater variation in DMI reported greater variation in methane output. Grainger et al. (2007) used both respiration chambers and the $\mathrm{SF}_{6}$ technique to measure methane output by lactating dairy cows fed ad libitum and reported that variability between cows was substantially higher than variability within cows, and was higher for the $\mathrm{SF}_{6}$ technique $(\mathrm{CV}=19.6 \%)$ than for the chamber technique $(\mathrm{CV}=$ $17.8 \%$ ).

Variability in methane output measured by the $\mathrm{SF}_{6}$ technique was greater in grazing animals than in housed animals in the analysis of Vlaming et al. (2005) who analyzed data from 643 sheep and dairy cows in 22 experiments and found a coefficient of variation of $25 \%$ for sheep and $21 \%$ for dairy cows indoors, compared with a coefficient of variation of $36 \%$ for sheep and $31 \%$ for dairy cows grazing outdoors.

In the current study, the coefficient of variation for MERm in the 215 cows observed over 5 mo, estimated from variance components of the mixed model, was $18.9 \%$ between cows and $11.5 \%$ within cows. These values are of similar magnitude to those found by Vlaming et al. (2005), Grainger et al. (2007), and Yan et al. (2010), but greater than levels of variation seen in studies involving respiration chambers with restricted feed intake (Blaxter and Clapperton, 1965). Feed intake could not be measured in the current study because cows were housed under commercial conditions, but the coefficient of variation for daily milk yield was $32.9 \%$, suggesting that variation in MERm could be associated with high variation in intake. Although the coefficient of variation for MERm is greater than for some respiration chamber studies, Clarke and Hannah (2007) demonstrated statistically that an increase in coefficient of variation for a measurement technique may not lessen the precision of the result, provided that more measurements are taken.

\section{Sources of Variation}

$\boldsymbol{B} W$, Milk Yield, and Feed Intake. Most studies agree that DMI is the main driver of daily methane output, although methane output per kilogram of DMI decreases with increasing feeding level (Blaxter and Clapperton, 1965; Grainger et al., 2007), with increasing diet digestibility (Blaxter and Clapperton, 1965; Yan et al., 2010), and with increasing proportions of concentrates or lipids in the diet (Moss et al., 1995; Beauchemin et al. 2009). In the current study, BW 
and milk yield accounted for significant proportions of variation in methane emissions. Both $\mathrm{BW}$ and milk yield were positively related to MERm, which, for milk yield, confirms our previous observations (Garnsworthy et al., 2012). It is likely that these effects are mediated through increasing DMI with increasing BW and milk yield, although differential responses to PMR and concentrate intakes would have reduced the strength of the relationship between milk yield and MERm because higher-yielding cows would have higher DMI, but also would have been offered more concentrates.

Diurnal Variation. Variation in MERm with time of milking (Figure 2) showed a distinct diurnal pattern that is remarkably similar to diurnal patterns seen in methane emissions for individual dairy cows in respiration chambers (Grainger et al., 2007), for groups of housed dairy cows monitored at ventilation inlets and outlets of barns (Kinsman et al., 1995; Amon et al., 2001), for grazing cattle monitored using point-source dispersion (McGinn et al., 2011), and for grazing cattle and sheep monitored in polytunnels (Lockyer, 1997). The fact that individual cows and groups of animals show similar diurnal patterns of methane emissions monitored with various techniques suggests that this variation is linked to an underlying pattern in animal behavior, digestive physiology, or ambient conditions.

For dairy cows housed in respiration chambers or in herds with traditional milking systems, both feeding and milking usually occur at fixed times each day, which induces a degree of synchrony among cows. In grazing dairy systems, milking times are usually fixed, and groups of grazing cattle and sheep normally exhibit set patterns of grazing, ruminating, and resting behavior (Lockyer, 1997). In the current study, although the time of fresh PMR allocation was the same for all cows, so feeding behavior might be synchronized, milking times were not; milking times must be different for every cow in a robotic milking system, and cows present themselves for milking throughout the $24 \mathrm{~h}$. Thus, the diurnal pattern in MERm is most likely related to time of PMR feeding, but not to pattern of milking times or concentrate feeding (concentrates were fed at each milking).

Ambient temperature and MERm followed similar diurnal patterns and were significantly correlated within days. Fluctuations in ambient temperature were greater between days, however, and were not correlated with mean daily MERm. Furthermore, the methane analyzer corrects concentrations for ambient temperature, and the temperature of air expelled from the cow's nostrils will be relatively constant compared with ambient temperature. We suggest, therefore, that diurnal variation in MERm is not caused by changes in ambient tem- perature, but is due to synchronized feeding behavior of the herd.

Because each individual cow was milked at different times of day and night, it could be surmised that milking pattern, or time since consuming PMR, might account for some of the variation between cows. The data do not support this supposition, however, because neither including time of milking in the model, nor adjusting MERm values for herd diurnal variation accounted for a significant portion of the residual variation in mean daily MERm. The likely explanation for this lack of effect is that the 2 to 4 milkings per cow per day occurred at times of low, medium, and high methane emissions, thus cancelling effects. Correction for diurnal variation might assume greater importance when MERm is measured in dairy herds where all cows are milked twice daily at fixed times.

Genetics. Variability among cows offers the potential for genetic selection of animals that have lower methane emissions per day or per unit of product. This is an attractive mitigation strategy because genetic improvements are cumulative and permanent. The possibility was dismissed by Martin et al. (2010), who concluded that the genetic component of methane production was low because ranking of animals for methane emissions was not consistent. However, their conclusion was drawn from studies with low numbers of animals: Goopy and Hegarty (2004) used 8 Angus steers; Münger and Kreuzer (2008) used 10 lactating cows from each of 3 breeds (Holstein, Simmental, and Jersey); and Vlaming et al. (2008) used 4 nonlactating Friesian $\times$ Jersey dairy cows. These studies found that ranking of animals for methane emissions changed over time or when animals were fed different diets.

In the current study, repeatability of ranking according to MERm for individual cows was high across time, and in Garnsworthy et al. (2012) it was high across diets. Furthermore, a significant sire effect was observed for a subset of cows with known pedigree when the specific sires were examined as a fixed effect. The lack of significance when sire was included as a random effect can be explained by the low level of replication within sires; more than half of the sires were represented by only 1 daughter. Consistent differences between animals are encouraging for possible genetic selection, but further studies are needed, with a greater number of cows under different environmental conditions, and with a more structured genetic population, before heritability can be estimated reliably. Should the findings be supported, it would not be difficult to screen large numbers of cows under commercial conditions. We estimate that a representative profile of individual cows in a whole herd could be obtained in 7 to $10 \mathrm{~d}$ using our method. 


\section{Estimated Daily Methane Emissions}

To provide information in units used in inventories, daily methane emissions were estimated from MERm data using the equation of Garnsworthy et al. (2012) to predict equivalent methane yields in respiration chambers. This approach is justified because cows were on the same dietary regimen in both studies, but further work is needed to validate equations for widespread use with different diets. The mean and range for estimated daily methane emissions were of similar magnitudes to those reported in other studies (e.g., Grainger et al., 2007; Yan et al., 2010).

The increase in estimated daily methane emissions over the first $10 \mathrm{wk}$ of lactation is consistent with expected increases in DMI as milk yield increases. The persistency of estimated methane emissions in later lactation does not, however, concur with expected decreases in DMI. A possible explanation is that although DMI might decrease in later lactation, the proportion of forage in the diet would be increasing, leading to higher methane emissions per unit of DMI.

The apparent decrease in estimated methane emissions after wk 20 of pregnancy is somewhat surprising. In energy evaluation systems, such as FiM (Thomas, 2004), pregnancy has an exponential additive effect on energy requirements, leading to prediction of increased GE intake above the requirements for milk production and maintenance. Weekly means shown in Figure 5 are outputs of the mixed model after adjustment for average BW and milk yield per cow, so the decrease in methane emissions with advancing pregnancy most likely reflects decreasing milk yield within cows.

Comparison of estimated daily methane emissions with IPCC (2006) predictions revealed poor agreement when considered at different weeks of lactation, although annual means were similar. It has to be acknowledged that IPCC (2006) is designed to estimate annual methane emissions, so BW is used only to predict energy requirements for maintenance, and energy requirements for pregnancy feature only as a function of maintenance. The main driver of IPCC-predicted methane emissions at different stages of lactation is, therefore, milk yield. Methane emissions predicted by using FiM equations showed much better agreement because BW change and stage of pregnancy contributed to prediction of energy requirements and energy intake; in early lactation, BW loss decreased energy requirements; in later lactation, BW gain and pregnancy increased energy requirements. Further work is required to confirm methane emissions estimated from MERm against measured energy intake at different stages of lactation. The current findings demonstrate, however, the importance of allowing for stage of lactation in any comparison of methane emissions between cows.

\section{CONCLUSIONS}

It is concluded that methane emissions vary considerably between dairy cows housed under commercial conditions, but ranking of cows for methane emissions is consistent across time. Variation is related to BW, milk yield, parity, and week of lactation, in accordance with changes in ME requirements. This variation needs to be taken into account when performing inventories or testing mitigation strategies, but variation might also offer opportunities for genetic selection.

\section{ACKNOWLEDGMENTS}

This work was funded by the Department for Environment, Food and Rural Affairs (London, UK; Project AC0219). We thank Adam Garnsworthy (TRIUMF, Vancouver, Canada) for development of data-handling software, Morag Hunter (University of Nottingham) for technical assistance, and the staff of the University of Nottingham Dairy Centre and the Biosciences Research Unit for assistance with care of the animals.

\section{REFERENCES}

Amon, B., Th. Amon, J. Boxberger, and Ch. Alt. 2001. Emissions of $\mathrm{NH}_{3}, \mathrm{~N}_{2} \mathrm{O}$ and $\mathrm{CH}_{4}$ from dairy cows housed in a farmyard manure tying stall (housing, manure storage, manure spreading). Nutr. Cycl. Agroecosyst. 60:103-113.

Beauchemin, K. A., T. A. McAllister, and S. M. McGinn. 2009. Dietary mitigation of enteric methane from cattle. CAB Rev.: Perspec. Agric. Vet. Sci. Nutr. Nat. Resour. 4:1-18.

Blaxter, K. L., and J. L. Clapperton. 1965. Prediction of the amount of methane produced by ruminants. Br. J. Nutr. 19:511-522.

Clarke, T., and M. C. Hannah. 2007. A simple statistical model to estimate precision of 300-day milk and fat production for dairy cows. Aust. J. Exp. Agric. 47:1095-1099.

Ellis, J. L., A. Bannink, J. France, E. Kebreab, and J. Dijkstra. 2010. Evaluation of enteric methane prediction equations for dairy cows used in whole farm models. Glob. Change Biol. 16:3246-3256.

Garnsworthy, P. C., J. Craigon, J. H. Hernandez-Medrano, and N. Saunders. 2012. On-farm methane measurements during milking correlate with total methane production by individual dairy cows. J. Dairy Sci. 95:3166-3180. http://dx.doi.org/10.3168/jds.20114605.

Goopy, J. P., and R. S. Hegarty. 2004. Repeatability of methane production in cattle fed concentrate and forage diets. J. Anim. Feed Sci. $13: 75-78$.

Grainger, C., T. Clarke, S. M. McGinn, M. J. Auldist, K. A. Beauchemin, M. C. Hannah, G. C. Waghorn, H. Clark, and R. J. Eckard. 2007. Methane emissions from dairy cows measured using the sulfur hexafluoride $\left(\mathrm{SF}_{6}\right)$ tracer and chamber techniques. J. Dairy Sci. 90:2755-2766.

IPCC (Intergovernmental Panel on Climate Change). 2006. 2006 IPCC Guidelines for National Greenhouse Gas Inventories. Prepared by the National Greenhouse Gas Inventories Programme. H. S. Eggleston, L. Buendia, K. Miwa, T. Ngara, and K. Tanabe, ed. 
Institute for Global Environmental Strategies (IGES), Hayama, Kanagawa, Japan.

Johnson, K., M. Huyler, H. Westberg, B. Lamb, and P. Zimmerman. 1994. Measurement of methane emissions from ruminant livestock using a sulfur hexafluoride tracer technique. Environ. Sci. Technol. 28:359-362.

Kinsman, R., D. Sauer, H. A. Jackson, and M. S. Wolynetz. 1995. Methane and carbon dioxide emissions from dairy cows in full lactation monitored over a six-month period. J. Dairy Sci. 78:27602766.

Lin, L. I. 1989. A concordance correlation coefficient to evaluate reproducibility. Biometrics 45:255-268.

Lockyer, D. R. 1997. Methane emissions from grazing sheep and calves. Agric. Ecosyst. Environ. 66:11-18.

Martin, C., D. P. Morgavi, and M. Doreau. 2010. Methane mitigation in ruminants: From microbe to the farm scale. Animal 4:351-365.

McGinn, S. M., D. Turner, N. Tomkins, E. Charmley, G. BishopHurley, and D. Chen. 2011. Methane emissions from grazing cattle using point-source dispersion. J. Environ. Qual. 40:22-27.

Moss, A. R., D. L. Givens, and P. C. Garnsworthy. 1995. The effect of supplementing grass silage with barley on digestibility, in sacco de- gradability, rumen fermentation and methane production in sheep at two levels of intake. Anim. Feed Sci. Technol. 55:9-33.

Münger, A., and M. Kreuzer. 2008. Absence of persistent methane emission differences in three breeds of dairy cows. Aust. J. Exp. Agric. 48:77-82.

Thomas, C. 2004. Feed Into Milk: A New Applied Feeding System for Dairy Cows. Nottingham University Press, Nottingham, UK.

Vlaming, J. B., H. Clark, and N. Lopez-Villalobos. 2005. The effect of $\mathrm{SF}_{6}$ release rate, animal species and feeding conditions on estimates of methane emissions from ruminants. Proc. N.Z. Soc. Anim. Prod. 65:4-8.

Vlaming, J. B., N. Lopez-Villalobos, I. M. Brookes, S. O. Hoskin, and H. Clark. 2008. Within- and between-animal variance in methane emissions in non-lactating dairy cows. Aust. J. Exp. Agric. $48: 124-127$.

Yan, T., C. S. Mayne, F. G. Gordon, M. G. Porter, R. E. Agnew, D. C. Patterson, C. P. Ferris, and D. J. Kilpatrick. 2010. Mitigation of enteric methane emissions through improving efficiency of energy utilization and productivity in lactating dairy cows. J. Dairy Sci. 93:2630-2638. 